(C) 2014 IEEE. Personal use of this material is permitted. Permission from IEEE must be obtained for all other uses, in any current or future media, including reprinting/republishing this material for advertising or promotional purposes, creating new collective works, for resale or redistribution to servers or lists, or reuse of any copyrighted component of this work in other works

\title{
Factors Affecting Product Quality and Reliability: A Comparison of Developed and Developing Countries
}

\author{
Pei-Lee. Teh ${ }^{1}$, Dotun. Adebanjo², Pervaiz K. Ahmed ${ }^{3}$ \\ ${ }^{1 \& 3}$ School of Business, Monash University, Selangor Darul Ehsan, Malaysia \\ ${ }^{2}$ Business School, University of Greenwich, London, United Kingdom
}

Email:1'teh.pei.lee@monash.edu, ${ }^{2}$ D.Adebanjo@greenwich.ac.uk, ${ }^{3}$ pervaiz.ahmed@monash.edu

\begin{abstract}
Increasing global competition has led to the need for organisations to continually improve their quality performance. In particular, developing countries such as China are focused on catching up with more developed countries. This study examines the relationships between improvement in three factors (health and safety conditions, worker motivation and satisfaction, work/life balance policies) in increase in product quality and reliability in developed countries. Based on a questionnaire, the study shows that improvement in health and safety conditions have a significant direct impact on increase in product quality and reliability while improvement in work/life balance do not have the same effect.
\end{abstract}

Keywords - Manufacturing, Developed Countries, Chian, Quality, Employee Motivation, working Conditions.

\section{INTRODUCTION}

This paper investigates the factors that affect product quality and reliability by contrasting between developed and developing countries. The study is based on data collected from the sixth edition of the International Manufacturing Strategy Survey (IMSS). The motivation for this study is based on the perceived differences in quality development between developing countries in Asia and western developed countries. According to [1], western countries are, at least, a decade ahead of Asian countries, except Japan, when it comes to quality management. A later study by, [2] also found that there were differences in quality management effectiveness when organisations in western countries are compared to their Asian counterparts. However, increased levels of outsourcing as well and increasing levels of demands for quality products by customers implies that manufacturers in developing economy countries such as China need to pay increasing attention to their quality management systems [3].

This study is based on the comparison of manufacturers in China with manufacturers in Germany and Denmark. Specifically, the study examines the relationships between motivation/human resource factors and product quality/reliability with a view to evaluating the effects of one set of factors on the other.

\section{LITERATURE REVIEW}

\section{A. 'Hard' and 'Soft' TQM}

Quality management has been argued to be a source of competitive advantage and a driver of global competition [4]. Researchers have long recognized that quality management factors can be classified into 'soft' and 'hard' factors [5]. While hard factors relate to the technical aspects of quality management, soft factors relate to the social or people-based aspects of quality management [6]. This study focuses on the 'soft' elements of TQM and in particular, workers' motivation and satisfaction, health and safety condition and work/life balance policies. These are particularly important factors because they relate to culture and it has been identified that culture affects how quality management is deployed and managed [7]. The potential differences between western and Asian approaches to culture were further highlighted by [8] who suggested that employees in some Asian countries may struggle when it comes to implementing quality management. Nevertheless, Asian countries and, in particular, major manufacturing countries such as China must continue to improve their 'soft' TQM development if they wish to remain globally competitive.

\section{B. Study Hypotheses}

According to [9], employee motivation and satisfaction is a cornerstone of quality development. Employees that are motivated and satisfied are not only likely to adopt the principles of quality management, they are also more likely to produce higher quality products and participate in quality improvement initiatives. Consequently, it is proposed that: 
H1a. Improvement in workers' motivation and satisfaction will lead to increase in product quality and reliability in developed country.

H1b. Improvement in workers' motivation and satisfaction will lead to increase in product quality and reliability in developing country.

Various studies including [10] and [11] have stressed the importance of organizational focus on the working conditions of employees, and in particular, the health and safety provisions of the organization. The study by [10] specifically discussed the situation in developing countries. While these studies have examined the issues of health and safety from the perspective of corporate social responsibility (CSR) and the supply chain pressure from customers in developed countries, they highlight the possibility of differences between organisations in developed and developing countries. This study suggests that unsafe working conditions can have an important impact on employee performance and consequently, product quality and reliability and it is proposed that:

H2a. Improvement in health and safety condition will lead to increase in product quality and reliability in developed country.

$H 2 b$. Improvement in health and safety condition will lead to increase in product quality and reliability in developing country.

According to [12], a key aspect of quality development is the alignment of human resource strategies with process-based quality management. The suggestion therefore is that the policies of the organization with respect to employee working practices can impact quality outcomes. Therefore, an organization needs to consider the impact that its policies will have on quality development. According to [10] and [11], one of these important policy factors relate to work/life balance and ensuring that employees do not work excessive hours. Therefore, it is proposed that:

H3a. Improvement in work/life balance policies will lead to increase in product quality and reliability in developed country.

H3b. Improvement in work/life balance policies will lead to increase in product quality and reliability in developing country.

In conclusion, there has been general agreement in the extant literature that 'soft' quality management factors play and important role in the development of quality in organisations. It has also been agreed that there are differences in the cultural issues between western and Asian organisations and that western organisations are more likely to be better quality developed than Asian organisations. However, Asian countries such as China have developed very rapidly in recent years and therefore, it is important to evaluate these cultural differences, if any, and the impact that they have on product quality and reliability.

\section{METHODOLOGY}

\section{A. Survey instrument and data collection}

The population of interest for this study is employees working in the manufacturing organizations. The empirical analysis of this study was based on data collected from the sixth edition of International Manufacturing Strategy Survey (IMSS). The sample consisted of plant, production, or operations managers from manufacturing organizations listed in the International Standard Industrial Classification (ISIC) codes ranging from 25, 26, 27, 28, 29 to 30. The survey items were adapted from items developed in previous literature [13-20]. All survey items were assessed using Likert scale. For example, the question for product quality and reliability, workers' motivation and satisfaction, health and safety condition (i.e., compared to three years ago the indicator has:) was measured on a five-point Likert scale where 1 represents decrease $(-5 \%$ or worse), 2 represents stayed about the same $(-5 \% /+5 \%), 3$ represents slightly increased (+5 to $+15 \%), 4$ represents increased $(+15 \%$ to $25 \%)$, and 5 represents strongly increased (+25\% or better). The question for work/life balance policies (i.e., effort in the last three years) was assessed on a five-point Likert scale where the anchors were $1=$ none and $5=$ high.

For the purpose of this study, a total of 112 data were analyzed. The breakdown of countries selected in this study is as follows: $44.6 \%$ were developed countries (i.e., Germany and Denmark) and 55.4\% were developing country (i.e., China).

\section{RESULTS}

The hypothesized model was tested using regression analysis (see: Fig. 1). The reliability was validated as the Cronbach Alpha was greater than 0.70. Principal component factor analysis was performed to assess the construct validity. Survey items had factor loadings between 0.708 and 0.803 , meeting the desirable value of 0.50 . The factorability of the correlation matrix was validated as the Bartlett test of sphericity was significant, and the Kaiser-Meyer-Olkin (KMO) measure of sampling adequacy was 0.70 . The descriptive analysis and correlation analysis are shown in Table I.

Stepwise regression analysis was performed to test the models: Model 1: Developed country; and Model 2: Developing country (see: Table III). As shown in Table II, the results of F-statistics indicated that the models fit the data. For model 1 , the value of $R$ square showed that the 
explanatory variables explained 34.4 per cent of the product quality and reliability. For model 2, the value of $R$ square indicated that the explanatory variables explained 67.6 per cent of the product quality and reliability.

For Model 1, improvement in health and safety condition $(\beta=0.344 ; p$-value $<0.05)$ was found to have a significant relationship with increase in product quality and reliability. Interestingly, improvement in workers' motivation and satisfaction $(\beta=0.034 ; p$-value $>0.10)$, and work/life balance policies $(\beta=0.032 ; p$-value $>0.10)$ had no effect on the increase in product quality and reliability. For Model 2, improvement in health and safety condition $(\beta=0.676 ; p$-value $<0.001)$, and workers' motivation and satisfaction $(\beta=0.225 ; p$-value $<0.10)$ had a positive relationship with increase in product quality and reliability. Similar to Model 1, there was an insignificant relationship between improvement in work/life balance policies and increase in product quality and reliability $(\beta$ $=-0.087, p>0.10$ ).

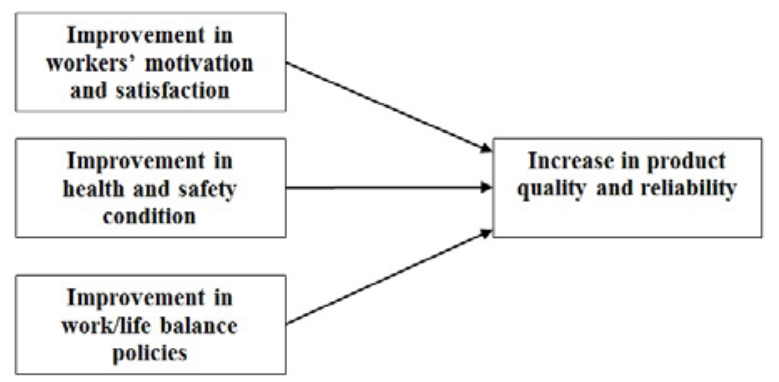

Fig. 1. Research model.

TABLE I

MEAN, STANDARD DEVIATION, CORRELATION MATRIX OF VARIABLES

\begin{tabular}{lllll}
\hline & PQ & WM & HS & WB \\
\hline PQ & 1 & & & \\
WM & $0.489^{* *}$ & 1 & & \\
HS & $0.609^{* *}$ & $0.610^{* *}$ & 1 & \\
WB & $0.250^{* *}$ & 0.173 & $0.227^{*}$ & 1 \\
Mean & 3.268 & 3.170 & 3.277 & 2.732 \\
SD & 0.900 & 0.899 & 0.932 & 1.162 \\
\hline
\end{tabular}

Note: ** Correlation is significant at the 0.01 level (2-tailed). * Correlation is significant at the 0.05 level (2-tailed). $\mathrm{PQ}=$ Increase in product quality and reliability; WM=Improvement in workers' motivation and satisfaction; HS=Improvement in health and safety condition; WB=Improvement in work/life balance policies; $\mathrm{SD}=$ Standard deviation.

TABLE II

SUMMARY OF MODELS

\begin{tabular}{lllll}
\hline Model & $R^{2}$ & Adj. $R^{2}$ & F-statistic & $p$-value \\
\hline 1 & $0.344^{\mathrm{a}}$ & 0.118 & 6.444 & $0.014^{* *}$ \\
2 & $0.676^{\mathrm{a}}$ & 0.456 & 50.373 & $0.000^{* * *}$ \\
\hline
\end{tabular}

Note: ${ }^{* *} p<0.05$; $* * * p<0.001$; ${ }^{a}$ Dependent variable $=$ Increase in product quality and reliability; Country moderator in Model 1=Developed country; Model 2=Developing country

TABLE III

RESULTS OF PATH ANALYSIS

\begin{tabular}{|c|c|c|c|c|}
\hline \multicolumn{2}{|c|}{ Model } & $\beta$ & $t$-value & $p$-value \\
\hline \multirow[t]{5}{*}{1} & Predictor variables & & & \\
\hline & $\begin{array}{l}\text { Improvement in health } \\
\text { and safety condition }\end{array}$ & 0.344 & 2.538 & $0.014 * *$ \\
\hline & Eliminated variables & & & \\
\hline & $\begin{array}{l}\text { Improvement in } \\
\text { workers' motivation } \\
\text { and satisfaction }\end{array}$ & 0.034 & 0.231 & 0.818 \\
\hline & $\begin{array}{lr}\text { Improvement } & \text { in } \\
\text { work/life } & \text { balance } \\
\text { policies } & \end{array}$ & 0.032 & 0.237 & 0.814 \\
\hline \multirow[t]{5}{*}{2} & Predictor variables & & & \\
\hline & $\begin{array}{l}\text { Improvement in health } \\
\text { and safety condition }\end{array}$ & 0.676 & 7.097 & $0.000 * * *$ \\
\hline & $\begin{array}{l}\text { Improvement in } \\
\text { workers' motivation } \\
\text { and satisfaction }\end{array}$ & 0.225 & 1.773 & $0.081 *$ \\
\hline & Eliminated variables & & & \\
\hline & $\begin{array}{lr}\text { Improvement } & \text { in } \\
\text { work/life } & \text { balance } \\
\text { policies } & \\
\end{array}$ & 0.087 & 0.873 & 0.386 \\
\hline
\end{tabular}

\section{DISCUSSION}

\section{A. Work/Life Balance Policies}

Overall, the results show that the level of focus on work/life balance does not have a significant direct impact on increases in product quality and satisfaction in both developed and developing countries. In many developed countries much of the drive for improved work/life balance has been driven by employees and government working directives that limit the number of hours that employees can work in a week (e.g. EU working hours directive). However, in developing countries, much of the drive has come from western customers, their customers and non-governmental pressure groups who have focused on corporate social responsibility (CSR) and tackling poor working practices in the supplier companies in China $[21,22]$. The fact that work/life balance policies do not have a significant direct impact on increasing product reliability and quality could imply three things. Firstly, the working directives and supply chain pressure currently in place implies that work/life balance is not an issue is not an issue in both developed and developing countries. Secondly, it could imply that employees are able to professionalize and compartmentalize their work life such that the amount of time spent working does not impact on their quality and level of output. Otherwise, thirdly, it 
could imply that while work/life balance does not directly impact product quality and reliability, it could indirectly impact it by having a significant relationship with other variables such as health and safety condition or workers motivation and satisfaction. Although, not tested in this study, the authors believe that the third scenario is the most plausible.

\section{B. Workers motivation and Satisfaction}

With respect to the relationships between improvement in workers motivation and satisfaction and their impact on increase in product quality and reliability, there is an important difference between developed and developing countries. While improvement in workers motivation and satisfaction (mean $=2.86$ ) as well as increase in product quality and reliability (mean $=2.84$ ) showed slight increase in developed countries, there was no significant relationship between these improvements. In contrast, with developing countries the increase in both product quality and reliability (mean= 3.61) and workers motivation and satisfaction (mean= 3.42) were higher and showed a significant relationship. In some respects, these results are not too surprising. Developed countries such as Germany and Denmark are already identified with high levels of quality and workers motivation and satisfaction and, consequently, the scope for improvement is less than would be applicable in countries lower down the performance spectrum. In contrast, China's fast growth, its desire to catch up with the rest of the world, increasing wages and the increasing demands of its international supply chain for higher quality products is starting to have a noticeable impact on workplace motivation/satisfaction and product quality. Perhaps, more importantly, the improvement in worker motivation and satisfaction is starting to impact product quality and reliability - an effect that was noticed in developed countries several years ago[23]. This fact that this effect does not appear in developed countries in the study may imply two things firstly, it may imply that as a country moves higher up the quality ladder, quality practices and procedures become engrained and the link with worker motivation and satisfaction becomes less tenuous. Secondly, it may imply that in countries like Germany and Denmark where manufacturers use more equipment automation in their operations, the ability of worker motivation and satisfaction to impact product quality and reliability becomes diminished.

\section{Health and Safety Condition}

The study shows that developing countries have a higher level of improvement in health and safety conditions (mean $=3.58$ ) when compared to developed countries (mean $=2.90$ ). Again, this is not too surprising given that countries like Germany and Denmark industralised much earlier on and have focused on health and safety conditions for a long time. In contrast, manufacturers in China need to improve much faster in order to catch up with developed countries when it comes to health and safety conditions. However, the study shows that for both developed and developing countries, the improvement in health and safety conditions had a direct significant impact on increase in product quality and reliability. The suggestion, therefore, is that in an environment where employees are safer or perceive greater safe working conditions, there are less likely to be problems with product quality and reliability.

\section{CONCLUSION}

To conclude, this paper has examined the impact of changes in health and safety conditions, workers motivation and satisfaction as well as work/life balance policies on changes in product quality and reliability by comparing developed and developing countries. The study has shown that greater focus on work/life balance policies have no significant direct impact on increase in product quality and reliability in both developed and developing countries. In contrast, improvement in health and safety conditions in both developed and developing countries have had significant direct impacts on increase in product quality and reliability. However, with respect to improvement worker motivation and satisfaction, only developing countries show a significant direct relationship with increase in product quality and reliability.

These findings have some industrial and academic implications. For industry, the message is that countries such as China are fast improving their production performance as well their human resource activities and over time, will start to catch up with more developed countries. However, it is important to note that manufacturers in developed countries are not static in their development and are also improving but at a slower rate. In addition, it should be noted that efforts to improve health and safety conditions are likely to lead to improvements in product quality, irrespective of country attributes. Academically, this study has indicated that there are still significant differences in manufacturing performance and activity between developed and developing countries and there is a need to continue to monitor if and when manufacturers in developing countries will catch up with their counterparts in developed countries.

This study has a limitation of focusing on only a limited number of countries and it is important to extend the study to other developed and developing countries in future. 
The authors wish to thank and acknowledge the contribution of project partners of the sixth edition of International Manufacturing Strategy Survey (IMSS). 


\section{REFERENCES}

[1] Huang, Y. S. and Lin, B. M. T, "An empirical investigation of total quality management: a Taiwanese case," The TQM magazine, vol. 14 No. 3, pp. 172-181, 2002.

[2] Kull, T., and J. Wacker, "Quality management effectiveness in asia: The influence of culture," Journal of Operations Management, vol. 28 no. 3, pp. 223-239, 2010.

[3] Lee, C. Y. and Zhou, X, "Quality management and manufacturing strategies in China," International Journal of Quality \& Reliability Management, vol. 17 no. 8, pp. 876-898, 2000.

[4] Prajogo, D. I. and Sohal, A. S., "The relationship between TQM practices, quality performance, and innovation performance an empirical examination," International Journal of Quality \& Reliability Management, vol. 20 no. 8, pp. 901918, 2003.

[5] Vecchi, A. and Brennan, L., "Quality Management: A cross-cultural perspective based on the GLOBE framework," International Journal of Operations and Production Management, vol. 31 no. 5, pp. 527-553, 2011.

[6] Rahman, S. and Bullock, P, "Soft TQM, hard TQM and organizational performance relationships: An empirical investigation," Omega, vol. 33 no. 1, pp. 73-83, 2005.

[7] Young, J. and Wilkinson, A, "In search of quality: The quality management experience in Singapore", International Journal of Quality and Reliability Management, vol. 18 no. 8, pp. 813835, 2001.

[8] Mathur, A., M. L. Mittal, and G. S. Dangayach, "Improving productivity in Indian SMEs," Production Planning \& Control, vol. 23, pp. 1011, 2012.

[9] Adebanjo, D. and Kehoe, D, "An evaluation of quality culture problems in UK companies," International Journal of Quality Science, vol. 3 no. 3, pp. 275-286, 1998.

[10] Laudal, T, “An attempt to determine the CSR potential of the International Clothing Business," Journal of Business Ethics, vol. 96, pp. 63-77, 2010.

[11] Baden, D., Harwood, I. and Woodward, D, "The effects of procurement policies on 'downstream' corporate social responsibility activity: contentanalytic insights into the views and actions of SME owner-managers," International Small Business Journal, vol. 29 no. 3, pp. 259-277, 2011.

[12] Laosirihongthong, T., Teh, P.L. and Adebanjo. D, "Revisiting quality management and performance', Industrial Management \& Data System, vol. 113 no. 7, pp. 990-1006, 2013.
[13] C. Gimenez, V. Sierra, and J. Rodon, "Sustainable operations: Their impact on the triple bottom line," International Journal of Production Economics, vol. 140, pp. 149-159, 2012.

[14] M. Pagell and D. Gobeli, "How Plant Managers' Experiences and Attitudes Toward Sustainability Relate to Operational Performance," Production and Operations Management, vol. 18, pp. 278299, 2009.

[15] D. Maxwell, W. Sheate, and R. van der Vorst, "Functional and systems aspects of the sustainable product and service development approach for industry," Journal of Cleaner Production, vol. 14, pp. 1466-1479, 2006.

[16] M. Longo, M. Mura, and A. Bonoli, "Corporate social responsibility and corporate performance: the case of Italian SMEs," Corporate Governance, vol. 5, pp. 28-42, 2005.

[17] J. U. Ahmed, "Modern approaches to product reliability improvement," The International Journal of Quality \& Reliability Management, vol. 13, pp. 27-41, 1996.

[18] F. Kimura, Y. Matoba, and K. Mitsui, "Designing Product Reliability based on Total Product Lifecycle Modelling," CIRP Annals Manufacturing Technology, vol. 56, pp. 163-166, 2007.

[19] S. McKenzie. (2004, Social Sustainability: Towards Some Definitions. 27. Available: https://atn.edu.au/Documents/EASS/HRI/workin g-papers/wp27.pdf

[20] D. Jamali, "A Stakeholder Approach to Corporate Social Responsibility: A Fresh Perspective into Theory and Practice," Journal of Business Ethics, vol. 82, pp. 213-231, 2008.

[21] F. Ciliberti, J. de Hann, D. de Groot, and P. Pontrandolfo, "CSR codes and the principalagent problem in supply chains: four case studies" Journal of Cleaner Production, vol. 19, pp. 889-894, 2011.

[22] F. Ciliberti, P. Pontrandolfo, and B. Scozzi, "Investigating corporate social responsibility in supply chains: a SME perspective," Journal of Cleaner Production, vol. 16, pp. 1571-1588, 2008.

[23] D. Adebanjo and D. Kehoe, "An investigation of quality culture development in UK industry," International Journal of Operations and Production Management, vol. 19, pp. 633-649, 1999. 